Published in final edited form as:

Curr Opin Nephrol Hypertens. 2017 May ; 26(3): 219-228. doi:10.1097/MNH.0000000000000318.

\title{
Clinical relevance of sarcopenia in chronic kidney disease
}

\author{
Ranjani N. Moorthi ${ }^{\mathrm{a}}$ and Keith G. Avin ${ }^{\mathrm{b}}$ \\ aDivision of Nephrology, Department of Medicine, Indiana University School of Medicine \\ bDepartment of Physical Therapy, Indiana University, Indianapolis, Indiana, USA
}

\begin{abstract}
Purpose of review-In this article, we review sarcopenia in chronic kidney disease (CKD). We aim to present how definitions of sarcopenia from the general population may pertain to those with CKD, its assessment by clinicians and emerging therapies for sarcopenia in CKD. For this review, we limit our description and recommendations to patients with CKD who are not on dialysis.
\end{abstract}

Recent findings-Poorer parameters of lean mass, strength and physical function are associated with worsening patient-centered outcomes such as limiting mobility, falls and mortality in CKD; however, the magnitude of these associations are different in those with and without CKD. Sarcopenia in CKD is a balance between skeletal muscle regeneration and catabolism, which are both altered in the uremic environment. Multiple pathways are involved in these derangements, which are briefly reviewed. Differences between commonly used terms cachexia, frailty, proteinenergy wasting, dynapenia and sarcopenia are described. Therapeutic options in predialysis CKD are not well studied; therefore, we review exercise options and emerging pharmacological therapies.

Summary-Sarcopenia, now with its own International Classification of Diseases, 10th Revision (ICD-10) code, is of importance clinically and should be accounted for in research studies in patients with CKD. Multiple therapies for sarcopenia are in development and will hopefully be available for our patients in the future.

\section{Keywords}

cachexia; muscle atrophy; muscle weakness; physical performance measures; protein-energy wasting

\section{INTRODUCTION}

Sarcopenia was a term coined by Irwin Rosenberg to mean 'paucity of flesh' (in Greek 'sarx' or flesh + 'penia' or loss). It refers to age-related decline in skeletal muscle [1]. A seemingly simple construct of age-related decline in skeletal muscle has been met by a plethora of operational definitions. To date, the term sarcopenia is primarily a research term.

Correspondence to Keith G. Avin, PhD, DPT, Assistant Professor of Physical Therapy, Department of Physical Therapy, Indiana University, 1140 W. Michigan St, CF-322, Indianapolis, IN 46202, USA. Tel: +1 317 278 9681; keigavin@iu.edu.

Conflicts of interest

There are no conflicts of interest. 
However, the recent development of an International Classification of Diseases, 10th Revision (ICD-10) code for sarcopenia highlights the need for uniformity and recognition of the underlying constructs by practicing clinicians. Age-related decline in skeletal muscle is confounded by disease, with estimates as high as $92 \%$ of older adults having at least one chronic disease [2]. Therefore, the definition of sarcopenia was adapted to include any loss of muscle tissue and function due to aging, chronic diseases (including cancer), low proteinenergy intake and physical inactivity. Chronic kidney disease (CKD) is a catabolic state, known to be associated with protein wasting and with multiple metabolic derangements due to uremia [3]. In addition, there may also be decreased muscle synthesis in the uremic milieu [3]. With the increasing prevalence of CKD, it is important for practicing nephrologists to be able to identify and quantify sarcopenia in their patients, as well as familiarize themselves with interventions to diminish its progression. In this review, we focus on definitions of sarcopenia in the general population, with special considerations in those patients with CKD, a brief review of the cause of skeletal muscle changes in CKD and the state of research for interventions.

\section{SARCOPENIA IN THE ELDERLY: OPERATIONAL DEFINITIONS}

Sarcopenia is the loss of skeletal muscle mass, strength and/or physical function. The cumulative effects of these changes in mass, strength and/or function range from decreased physical activity to decreased mobility, disability, falls, repeated hospitalizations and even mortality [4]. Clinically, questions arise as to which assessments should be completed to diagnose a patient with sarcopenia, and various international committees and working groups provide their measurement recommendations and cutoffs, which tend to be combinations of muscle mass, strength and function [5-7].

Sarcopenia may be simply the loss of skeletal muscle mass, which can be assessed using bioelectrical impedance analysis (BIA), whole body dual-energy x-ray absorptiometry (DXA), BMI or circumferential or caliper-based methods; each method with multiple validated calculation methodology. Sarcopenia may also include decrements in isometric, isokinetic or isotonic muscle strength assessed commonly at the hand (i.e. grip strength) or knee. In addition, definitions can include assessments of physical performance. Physical performance can be measured in clinic using multiple simple tests. In fact, 'gait speed assessment' has been termed the fifth vital sign in the elderly due to its ease of measurement and its significant relationship with long-term outcomes. In a large pooled analysis of nine cohort studies of older adults (34,485 patients), Studenski et al. [6] showed that overall hazards for survival per $0.1 \mathrm{~m} / \mathrm{s}$ higher gait speed was 0.88 [95\% confidence interval (CI): $0.87-0.90 ; P<0.001]$. Similarly, faster gait speed has been shown to be associated with decreased risks of developing mobility limitations, as well as of disability performing activities of daily living in the older adult [8]. Therefore, there is value in assessing sarcopenia to help predict risk of mobility loss as well as declines in functional status in the elderly. The patients most at risk may benefit the most from preemptively, individually tailored therapeutic interventions. Refer to Table 1 for a list of operational definitions of sarcopenia in the general population by major international working groups. The variability in definitions is, in part, a reason behind the clinical roadblock in defining sarcopenia. 


\section{SARCOPENIA IN CHRONIC KIDNEY DISEASE: OPERATIONAL DEFINITIONS}

CKD is often called a model of 'accelerated aging'; therefore, it is likely that the direction of relationships between loss of lean mass, skeletal muscle strength and physical performance (all components of sarcopenia) and patient-centered outcomes such as mobility limitation, disability and mortality is the same as in the general population. However, the magnitudes of these associations are likely different in CKD from those in the general population. Therefore, the cutoffs for lean mass, muscle strength and physical performance in CKD to define patients seen in clinic as 'sarcopenic' or 'not sarcopenic' are not quite as clear as in the general population. For example, data from the Korean National Health and Nutrition Examination Surveys found that sar-copenia was prevalent in both men and women $(P<$ 0.001), but the stage of CKD was significantly associated with increased prevalence of sarcopenia in men only [14]. The lack of association between stage of CKD and prevalence of sarcopenia in women may be due to the operational definition used in this study: appendicular skeletal muscle mass as a percentage of body weight 2 SDs below the sexspecific mean for young adults. Further, the emphasis upon body composition while excluding muscle strength and/or performance measures may have biased the results toward men. Another example of how operational definitions can impact the diagnosis of sarcopenia was demonstrated by Pereira et al. [15]. They defined sarcopenia as reduced hand grip strength and low skeletal muscle mass index. Skeletal muscle mass index was identified by one of the following three assessments: subjective global assessment, mid-arm muscle circumference [(MAMC) $90 \%$ reference value] or BIA (BIA $<10.76 \mathrm{~kg} / \mathrm{m}^{2}$ men; $<6.76$ $\mathrm{kg} / \mathrm{m}^{2}$ women). Interestingly, the prevalence of sarcopenia varied dependently upon the employed method for muscle mass index, with BIA measured prevalence of sarcopenia lower than that measured by subjective global assessment and mid-arm circumference. Patients with CKD may have volume expansion, which affects BIA, whereas DXAmeasured lean mass is not affected [16].

There are a limited number of studies that have examined consequences of sarcopenia in predialysis CKD. In the Pereira et al. [15] study above, sarcopenia measured by muscle mass index, using BIA and hand grip strength, was associated with a Hazard Ratio (HR) for mortality of 3.02 (95\% CI: 1.30-7.05, $n=287$ ). To further illustrate the need for operational definitions for sarcopenia in CKD, when muscle mass was calculated using subjective global assessment, sarcopenia was associated with a HR for mortality of 1.8 (95\% CI: 0.78-4.17) and 1.62 (95\% CI: 0.69-3.82) when mid-arm circumference was used [15]. In a study of 385 patients with mean estimated glomerular filtration rate (eGFR) $41 \mathrm{ml} / \mathrm{min} / 1.73 \mathrm{~m}^{2}$, each 0.1 $\mathrm{m} / \mathrm{s}$ decrement in gait speed was associated with a $26 \%$ higher risk for death, and each 1-s longer timed up and go was associated with an $8 \%$ greater risk for mortality [17]. In another study of 128 predialysis CKD patients followed for a median 2.8 years, decreased hand grip strength was independently associated with the composite outcome of progression to endstage kidney disease and mortality in men and women and across different stages of predialysis CKD [18]. In summary, sarcopenia is associated with important clinical outcomes in CKD and needs to be accounted for both in research studies as well as in clinical practice. 


\section{SARCOPENIA ICD-10}

Recently an ICD-10 code was developed for the diagnosis of sarcopenia. Although the development of the code demonstrates its clinical importance. the lack of uniformity across the definitions of sarcopenia makes implementation quite challenging, especially in patients with CKD. The lack of definition is essentially an opportunity for flexibility to fit clinical presentation with available resources. As depicted in Table 1, the overall consensus is that sarcopenia is diagnosed with some measure of lean mass (i.e. DEXA and BIA) and/or physical function (i.e. grip strength and gait speed). For many clinical situations, DEXA and/or BIA are not clinically feasible due to time and/or cost. Therefore, resources could be made available for physical function and strength assessments. Although there are no established cutoff scores for the population with CKD, it is important to track individual progress/regression of sarcopenia measures. As described in the studies in the predialysis population, poorer scores on these tests are associated with poor clinical outcomes $[15,17,18]$. To our knowledge, patient-centered outcomes (e.g. loss of mobility, impaired ADLS, falls etc.) have not been studied with serial measures of sarcopenia in predialysis CKD. However, extrapolating data from the community-dwelling older adults and patients with peripheral artery disease, it is likely that worsening trends in strength and physical function parameters are associated with these important patient-centered outcomes [19-21]. Clinically, usual gait speed over 4-8 $\mathrm{m}$ and grip strength are two examples that are easily and efficiently implemented. Table 2 highlights additional examples of measures of sarcopenia that could be measured in the nephrologist's office.

\section{OTHER TERMINOLOGY FOR SKELETAL MUSCLE LOSS}

A number of similar constructs aim to describe changes of the musculoskeletal system with aging and disease, including dynapenia, protein-energy wasting (PEW), frailty and cachexia. These terms have been used when describing changes in muscle atrophy and performance of patients with CKD. The aim of this current section is to present each construct that is related to muscle loss and utilize Tables 3 and 4 to demonstrate similarities and differences amongst these potentially confusing terms.

Dynapenia is formed from the Greek words of 'dyna' (power, strength or force) and 'penia' (poverty) [4]. This construct is important as there is not always a linear relationship between skeletal muscle size and strength [24]. Muscle strength, power and performance are the culmination of multiple components of skeletal muscle including size, fiber type, quality, innervation and pennation (i.e. muscle fiber angle). Therefore, even if a patient demonstrates within normal limits in muscle/body composition, they may still be weak in functional activities or activities of daily living, given potential impairments of other components of muscle function. The diagnosis of this condition would focus on identifying a loss of muscle strength or power, regardless of muscle size.

PEW was a term proposed by the International Society of Renal Nutrition and Metabolism [25]. PEW is a syndrome that consists of nutritional and metabolic abnormalities in patients with CKD, but is more common in those with end-stage renal disease. Similar to cachexia and sarcopenia, PEW is associated with high morbidity and mortality [26]. Although 
insufficient food intake due to poor appetite and dietary restrictions contributes to malnutrition, the pathophysiology of PEW cannot be fully explained by undernutrition. The diagnosis of PEW is based upon satisfying three of the following four criteria: biochemical indicators (i.e. albumin and cholesterol), low/reduced body weight or fat mass, decreased muscle mass and low protein/energy intake.

Frailty is described as a multidimensional phenomenon that reflects declining physical function and vulnerability to adverse outcomes in the setting of stress, such as illness or hospitalization [27]. Frailty may be defined as having three out of the following five components: low body weight for height $\left(\leq 8.5 \mathrm{~kg} / \mathrm{m}^{2}\right)$; slow walking; weakness, defined subjectively or objectively; exhaustion and low physical activity. Often the diagnosis of frailty is based upon subjective assessment of weakness, exhaustion and physical activity, which may cause limitations. The key in frailty is the vulnerability to stressors and is viewed as further along in the spectrum of impairment as compared with dynapenia and sarcopenia.

Cachexia is defined as 'a multifactorial syndrome characterized by an ongoing loss of skeletal muscle mass (with or without loss of fat mass) that cannot be fully reversed by conventional nutritional support and leads to progressive functional impairment' [28]. The key features of cachexia are inflammation and weight loss in adults (or growth failure in children), that is distinct from anorexia or starvation. Cachexia is diagnosed as weight loss more than $5 \%$ over the past 6 months or reduced BMI (>20 points), and three of the following five additional criteria: decreased muscle strength, fatigue, anorexia, low fat-free mass index and abnormal biochemistry (i.e. inflammatory markers, anemia and albumin) [29]. The weight loss in cachexia has been specifically noted to not be result of age-related loss of muscle mass, malabsorption or hyperthyroidism. Given these features are quite common in those with CKD, the utility of the term cachexia remains to be seen. Further, the terms and definitions of sarcopenia and PEW overlap with cachexia and create multiple discussions of utility and potential confusion. As per the definition, most patients who are diagnosed with cachexia will be sarcopenic, but not vice versa [30]. Cachexia is a term commonly utilized for patients with cancer, but it is not clear how well this term will be utilized in the care for those with CKD.

The overlapping constructs from dynapenia to cachexia may cause confusion, but also aide in appropriate management. A patient who is diagnosed with sarcopenia will benefit from physical therapy to improve muscle mass and function, whereas a patient with PEW or cachexia will benefit from greater involvement of nutrition to combat the significant loss of mass. Currently, there are many overlapping mechanisms for the loss of muscle and body mass, and it is not clear if different pharmacological or physical therapies should unique to the underlying pathophysiology.

\section{PATHOPHYSIOLOGY OF SARCOPENIA IN CHRONIC KIDNEY DISEASE}

The underlying mechanisms of sarcopenia in the context of CKD revolve around the loss of muscle mass. This is a 'chicken-or-the-egg' conundrum, as it is unknown whether reduced physical activity causes muscle loss or loss of muscle causes reduced activity. Regardless of the initiating factor, the loss of muscle mass in CKD may be attributed to a negative balance 
of protein homeostasis (Fig. 1), that is increased catabolism and decreased synthesis of muscle. 'Normal' aging has been shown to impair skeletal muscle 'regeneration', which is the formation of new myofibers from dormant satellite cells in skeletal muscle [31]. CKD is also associated with impaired regeneration (reduced cell activation and expression of myogenic regulatory factors) [32]. Muscle regeneration and size have been shown to be effected by myostatin, a negative regulator of skeletal muscle mass. Myostatin is increased in the blood of patients with CKD and may be a target of pharmacological interventions. Hypogonadism is common in CKD and is associated with reduced muscle mass and strength $[33,34]$ and is another target for skeletal muscle intervention in CKD.

In addition to impaired regeneration, increased catabolism is common in CKD and attributed to a number of factors: accumulation of uremic toxins, chronic inflammation, insulin resistance, hormonal imbalance, malnutrition, vitamin D deficiency, oxidative stress and increased ubiquitination [35]. Vitamin D deficiency can upregulate the ubiquitin-proteasome (UPS) pathway leading to protein degradation and subsequently, skeletal muscle atrophy [36]. The renin-angiotensin-aldosterone system is upregulated in CKD and impairs muscle regeneration and increases UPS proteolytic pathways $[37,38]$. The UPS pathway degrades and digests ubiq-uitinated proteins through the activation of nuclear forkhead box members (FOXOs). In CKD, FOXO1 has been shown to play a role in CKD-related muscle wasting and could be a potential therapeutic target in future clinical studies [39]. It is also important to note that patients with CKD often have comorbidities such as cardiomyopathy that also share pathways with sarcopenia such as oxidative stress and ghrelin, leptin and cytokine release [40].

\section{INTERVENTIONS AND EMERGING THERAPIES FOR SARCOPENIA IN CHRONIC KIDNEY DISEASE}

\section{Aerobic and resistance exercise}

Exercise and exercise capacity have been shown to be important in the development of CKD demonstrated by an inverse relationship between exercise capacity and CKD incidence; the risk of CKD was $22 \%$ lower for every one metabolic equivalent increase in exercise capacity [41]. Further, lifestyle factors such as physical activity, smoking, no bedtime snacking and habitual moderate exercise were associated with reduced CKD incidence. [42]. Although not an exhaustive list, a few examples of recent exercise studies in CKD have been provided (Table 5). In a recent Cochrane review, exercise interventions were administered in patients on dialysis in 45 of 59 randomized controlled trials (RCTs), whereas a smaller proportion included patients with CKD predialysis (11 of 59 RCTs) [48]. In the predialysis population, the following exercise types were used: aerobic (six studies), resistance training (three studies), and aerobic and resistance (two studies). The conclusion was that there were insufficient data to support a role of exercise mitigating CKD progression but there was evidence for aerobic exercise improving aerobic capacity (VO2peak) and health-related quality of life. In another review that focused on six studies that performed aerobic and resistance exercise intervention in patients not yet on dialysis, the conclusion was that the results were conflicting and plagued by small sample size [49]. Although patients undergoing dialysis are a more convenient population to study, greater efforts should be 
made to study the predialysis population, as exercise interventions prior to dialysis may improve functional status once dialysis is initiated. To evaluate resistance training in patients with stages 3-5 CKD, Cheema et al. [50] performed a systematic review that identified increases in both muscle strength and quality of life. A secondary analysis in this systematic review identified that muscle cross-sectional area was increased (i.e. hypertrophy) following progressive resistance training of the lower extremities. These results are promising and shows evidence that exercise can be beneficial for patients with CKD. However, further studies are needed to determine to what extent exercise can impact CKD progression and what types of exercise are optimal for this population.

\section{PHARMACOLOGICAL INTERVENTIONS}

Myostatin is a myokine and an inhibitor of skeletal muscle growth [51]. In a 5/6 nephrectomy mouse model, subcutaneous myostatin antibody injections $(5 \mathrm{mg} / \mathrm{kg})$ had multiple beneficial effects upon skeletal muscle, including reduced protein degradation, increased protein synthesis and improved satellite cell function [52]. In postmenopausal healthy volunteers, a single dose of a soluble form of activin receptor type IIB that binds myostatin led to an increase in thigh muscle volume and lean mass [53]. However, a randomized clinical trial that used the same compound on those diagnosed with Duchenne muscular dystrophy, had to be stopped early due to non muscle side effects (i.e. epistaxis and telangiectasias) despite a trend towards improved lean mass and 6-min walk test. [54]. Phase 2 humanized mAb against myostatin LY2495655 showed dose-dependent and significant increases in appendicular leanmass atweeks 8 and 16 as compared with placebo after total hip arthroplasty randomized clinical trial of 400 patients. [55] A pilot RCT study of PINTA 745 , an antimyostatin peptibody, in patients undergoing hemodialysis has completed recruiting, but results are not yet published (www.clinicaltrials.gov NCT01958970). The primary outcome is percentage change in lean mass using DXA after 4 weeks of treatment. To our knowledge, this is the only study in patients with kidney disease. Hopefully, myostatin antagonism will be tested in patients with predialysis CKD in the future.

As discussed above, androgens such as testosterone may be important to maintain skeletal muscle mass through their effects on muscle protein synthesis [56]. In dialysis patients, nandrolone decanoate treatment has shown to improve skeletal muscle mass, both by itself as well as combined with resistance exercise [57,58]. Studies are lacking as to the role of androgen supplementation in patients not yet on dialysis combined with or without exercise regimens. An anabolic steroid with lower androgenic effect, oxymetholone, was tested in 43 hemodialysis patients in a RCT of 24-week duration and showed a significant increase in grip strength, subjective scores of physical function and an increase in mRNA levels for myosin heavy chain, Insulin-like growth factor 1 (IGF-1) and II receptors. Adverse effects included increase in liver enzymes [59]. Future studies need to be performed in CKD of both androgens and anabolic steroids, especially to assess benefits versus risks for those with CKD and sarcopenia. Selective androgen receptor (AR) modulators, with a favorable muscle anabolic selectivity profile but lower systemic side effects are being tested in the healthy elderly patients and in cancer-associated sarcopenia [60,61]. In the Phase 2 study in elderly patients, there was improvement in physical function and lean mass with enobosarm, a selective AR modulator after 12 weeks. 
Vitamin D supplementation improved physical function measured by the stair climb test, timed-up-and-go and gait speed in both CKD and dialysis patients [62]. However, larger, more generalizable trials of vitamin D supplementation for sarcopenia are lacking. Finally, growth hormone supplementation is another intervention that is potentially helpful in skeletal muscle synthesis in dialysis patients, but requires randomized controlled investigation in predialysis CKD $[63,64]$.

\section{ROLE OF NEPHROLOGISTS}

A recent survey showed that though $61.2 \%$ of polled nephrologists felt that their patients' physical activity was poor, $53 \%$ did not prescribe exercise to dialysis patients. As would be expected, the majority did not receive training regarding exercise in their medical school or residency [65]. Another survey of nephrologists also showed that a lack of time while rounding in dialysis units and a significant number believed that other 'medical' issues were more important than the lack of physical activity [66]. Once sarcopenia is identified it is important to combat it with interventions lead by exercise and nutrition professionals. In patients undergoing dialysis, a structured physical therapy program has been shown to increase distance walked on the 6-min walk test and in quadriceps strength [67,68]. It is unclear if these results are generalizable to predialysis CKD patients. However, these studies suggest that collaboration with those who are knowledgeable in exercise and rehabilitation, such as physical therapists, may benefit the patient. Further, increased awareness and education regarding physical activity, muscle performance, exercise and frailty at the level of medical school, residency and Nephrology fellowship programs may be warranted to improve patient quality of life.

\section{CONCLUSION}

Sarcopenia in CKD, though not well defined, is very important with respect to its relationship with patient-centered outcomes of mobility limitations, functional limitations in activities of daily living, hospitalizations, fractures and mortality. Specific cutoffs for assessments that define sarcopenia in the CKD population are unknown, but individual patient trends may be of similar importance. There are many simple physical function and muscle function tests that can be performed in the nephrologist's office without adding more than a few minutes to patient encounters. Performance on tests such as these will allow prescription of individualized exercise regimens, and use of physical therapy and nutritional interventions that may prove to be beneficial. Finally, pharmacological interventions that inhibit muscle wasting as well as increase new muscle formation are in trials in the general population and patients undergoing dialysis. Further research is needed to identify beneficial outcomes for patients with CKD.

\section{Acknowledgments}

We would like to thank Dr Sharon Moe for her assistance with this review.

Financial support and sponsorship 
The work was supported by the K23 DK102824-01A1 Longitudinal Assessment of Skeletal Muscle Physiology in Dialysis Patients, Granting Agency: NIDDK (author: R.N.M.) as well as K08 DK110429-01 Mechanisms of Interventions to Ameliorate Sarcopenia in Chronic Kidney Disease, Granting Agency: NIDDK (author: K.G.A.).

\section{References}

1. Rosenberg IH. Sarcopenia: origins and clinical relevance. J Nutr. 1997; 127(5 Suppl):990S-991S. [PubMed: 9164280]

2. Hung WW, Ross JS, Boockvar KS, Siu AL. Recent trends in chronic disease, impairment and disability among older adults in the United States. BMC Geriatr. 2011; 11:47. [PubMed: 21851629]

3. Wang XH, Mitch WE. Mechanisms of muscle wasting in chronic kidney disease. Nat Rev Nephrol. 2014; 10:504-516. [PubMed: 24981816]

4. Clark BC, Manini TM. Functional consequences of sarcopenia and dynapenia in the elderly. Curr Opin Clin Nutr Metab Care. 2010; 13:271-276. [PubMed: 20154609]

5. Cruz-Jentoft AJ, Baeyens JP, Bauer JM, et al. Sarcopenia: European consensus on definition and diagnosis: report of the European Working Group on Sarcopenia in Older People. Age Ageing. 2010; 39:412-423. [PubMed: 20392703]

6. Studenski SA, Peters KW, Alley DE, et al. The FNIH sarcopenia project: rationale, study description, conference recommendations, and final estimates. J Gerontol A Biol Sci Med Sci. 2014; 69:547-558. [PubMed: 24737557]

7. Dam TT, Peters KW, Fragala M, et al. An evidence-based comparison of operational criteria for the presence of sarcopenia. J Gerontol A Biol Sci Med Sci. 2014; 69:584-590. [PubMed: 24737561]

8. Perera S, Patel KV, Rosano C, et al. Gait speed predicts incident disability: a pooled analysis. J Gerontol A Biol Sci Med Sci. 2016; 71:63-71. [PubMed: 26297942]

9. Baumgartner RN, Koehler KM, Gallagher D, et al. Epidemiology of sarcopenia among the elderly in New Mexico. Am J Epidemiol. 1998; 147:755-763. [PubMed: 9554417]

10. Newman AB, Kupelian V, Visser M, et al. Sarcopenia: alternative definitions and associations with lower extremity function. J Am Geriatr Soc. 2003; 51:1602-1609. [PubMed: 14687390]

11. Delmonico MJ, Harris TB, Lee JS, et al. Alternative definitions of sarcopenia, lower extremity performance, and functional impairment with aging in older men and women. J Am Geriatr Soc. 2007; 55:769-774. [PubMed: 17493199]

12. Muscaritoli M, Anker SD, Argiles J, et al. Consensus definition of sarcopenia, cachexia and precachexia: joint document elaborated by Special Interest Groups (SIG) 'cachexia-anorexia in chronic wasting diseases' and 'nutrition in geriatrics'. Clin Nutr. 2010; 29:154-159. [PubMed: 20060626]

13. Fielding RA, Vellas B, Evans WJ, et al. Sarcopenia: an undiagnosed condition in older adults. Current consensus definition: prevalence, etiology, and consequences. International Working Group on Sarcopenia. J Am Med Dir Assoc. 2011; 12:249-256. [PubMed: 21527165]

14. Moon SJ, Kim TH, Yoon SY, et al. Relationship between stage of chronic kidney disease and sarcopenia in Korean aged 40 years and older using the Korea National Health and Nutrition Examination Surveys (KNHANES IV-2, 3, and V-1, 2), 2008-2011. PLoS One. 2015; 10:e0130740. [PubMed: 26083479]

15. Pereira RA, Cordeiro AC, Avesani CM, et al. Sarcopenia in chronic kidney disease on conservative therapy: prevalence and association with mortality. Nephrol Dial Transplant. 2015; 30:1718-1725. [PubMed: 25999376]

16. de Fijter CW, de Fijter MM, Oe LP, et al. The impact of hydration status on the assessment of lean body mass by body electrical impedance in dialysis patients. Adv Perit Dial. 1993; 9:101-104. [PubMed: 8105899]

17. Roshanravan B, Robinson-Cohen C, Patel KV, et al. Association between physical performance and all-cause mortality in CKD. J Am Soc Nephrol. 2013; 24:822-830. [PubMed: 23599380]

18. Chang YT, Wu HL, Guo HR, et al. Handgrip strength is an independent predictor of renal outcomes in patients with chronic kidney diseases. Nephrol Dial Transplant. 2011; 26:3588-3595. [PubMed: 21444362] 
19. Kozakai R, von Bonsdorff M, Sipila S, Rantanen T. Mobility limitation as a predictor of inpatient care in the last year of life among community-living older people. Aging Clin Exp Res. 2013; 25:81-87. [PubMed: 23740637]

20. Toots A, Rosendahl E, Lundin-Olsson L, et al. Usual gait speed independently predicts mortality in very old people: a population-based study. J Am Med Dir Assoc. 2013; 14:529.e1-529.e6. [PubMed: 23706405]

21. McDermott MM, Liu K, Ferrucci L, et al. Decline in functional performance predicts later increased mobility loss and mortality in peripheral arterial disease. J Am Coll Cardiol. 2011; 57:962-970. [PubMed: 21329843]

22. Reese PP, Cappola AR, Shults J, et al. Physical performance and frailty in chronic kidney disease. Am J Nephrol. 2013; 38:307-315. [PubMed: 24107579]

23. Hsiao SM, Tsai YC, Chen HM, et al. Association of fluid status and body composition with physical function in patients with chronic kidney disease. PLoS One. 2016; 11:e0165400. [PubMed: 27798648]

24. Delmonico MJ, Harris TB, Visser M, et al. Longitudinal study of muscle strength, quality, and adipose tissue infiltration. Am J Clin Nutr. 2009; 90:1579-1585. [PubMed: 19864405]

25. Fouque D, Kalantar-Zadeh K, Kopple J, et al. A proposed nomenclature and diagnostic criteria for protein-energy wasting in acute and chronic kidney disease. Kidney Int. 2008; 73:391-398. [PubMed: 18094682]

26. Bonanni A, Mannucci I, Verzola D, et al. Protein-energy wasting and mortality in chronic kidney disease. Int J Environ Res Public Health. 2011; 8:1631-1654. [PubMed: 21655142]

27. Fried LP, Tangen CM, Walston J, et al. Frailty in older adults: evidence for a phenotype. J Gerontol A Biol Sci Med Sci. 2001; 56:M146-M156. [PubMed: 11253156]

28. Fearon K, Strasser F, Anker SD, et al. Definition and classification of cancer cachexia: an international consensus. Lancet Oncol. 2011; 12:489-495. [PubMed: 21296615]

29. MacDonald N. Terminology in cancer cachexia: importance and status. Curr Opin Clin Nutr Metab Care. 2012; 15:220-225. [PubMed: 22466925]

30. Rolland Y, Abellan van Kan G, Gillette-Guyonnet S, Vellas B. Cachexia versus sarcopenia. Curr Opin Clin Nutr Metab Care. 2011; 14:15-21. [PubMed: 21076295]

31. Barberi L, Scicchitano BM, De Rossi M, et al. Age-dependent alteration in muscle regeneration: the critical role of tissue niche. Biogerontology. 2013; 14:273-292. [PubMed: 23666344]

32. Avin KG, Chen NX, Organ JM, et al. Skeletal muscle regeneration and oxidative stress are altered in chronic kidney disease. PLoS One. 2016; 11:e0159411. [PubMed: 27486747]

33. Carrero JJ, Qureshi AR, Nakashima A, et al. Prevalence and clinical implications of testosterone deficiency in men with end-stage renal disease. Nephrol Dial Transplant. 2011; 26:184-190. [PubMed: 20624775]

34. Cigarran S, Pousa M, Castro MJ, et al. Endogenous testosterone, muscle strength, and fat-free mass in men with chronic kidney disease. J Ren Nutr. 2013; 23:e89-e95. [PubMed: 23046736]

35. Avin KG, Moorthi RN. Bone is not alone: the effects of skeletal muscle dysfunction in chronic kidney disease. Curr Osteoporos Rep. 2015; 13:173-179. [PubMed: 25691218]

36. Bhat M, Kalam R, Qadri SS, et al. Vitamin D deficiency-induced muscle wasting occurs through the ubiquitin proteasome pathway and is partially corrected by calcium in male rats. Endocrinology. 2013; 154:4018-4029. [PubMed: 23928374]

37. Graziani G, Badalamenti S, Del Bo A, et al. Abnormal hemodynamics and elevated angiotensin II plasma levels in polydipsic patients on regular hemodialysis treatment. Kidney Int. 1993; 44:107114. [PubMed: 8355450]

38. Sanders PM, Russell ST, Tisdale MJ. Angiotensin II directly induces muscle protein catabolism through the ubiquitin-proteasome proteolytic pathway and may play a role in cancer cachexia. $\mathrm{Br} \mathrm{J}$ Cancer. 2005; 93:425-434. [PubMed: 16052213]

39. Xu J, Li R, Workeneh B, et al. Transcription factor FoxO1, the dominant mediator of muscle wasting in chronic kidney disease, is inhibited by micro-RNA-486. Kidney Int. 2012; 82:401-411. [PubMed: 22475820]

40. Collamati A, Marzetti E, Calvani R, et al. Sarcopenia in heart failure: mechanisms and therapeutic strategies. J Geriatr Cardiol. 2016; 13:615-624. [PubMed: 27605943] 
41. Kokkinos P, Faselis C, Myers J, et al. Exercise capacity and risk of chronic kidney disease in US veterans: a cohort study. Mayo Clin Proc. 2015; 90:461-468. [PubMed: 25792243]

42. Michishita R, Matsuda T, Kawakami S, et al. The association between unhealthy lifestyle behaviors and the prevalence of chronic kidney disease (CKD) in middle-aged and older men. $\mathrm{J}$ Epidemiol. 2016; 26:378-385. [PubMed: 26947951]

43. Van Craenenbroeck AH, Van Craenenbroeck EM, Van Ackeren K, et al. Effect of moderate aerobic exercise training on endothelial function and arterial stiffness in CKD stages 3-4: a randomized controlled trial. Am J Kidney Dis. 2015; 66:285-296. [PubMed: 25960303]

44. Gregory SM, Headley SA, Germain M, et al. Lack of circulating bioactive and immunoreactive IGF-I changes despite improved fitness in chronic kidney disease patients following 48 weeks of physical training. Growth Horm IGF Res. 2011; 21:51-56. [PubMed: 21251861]

45. Headley S, Germain M, Wood R, et al. Short-term aerobic exercise and vascular function in CKD stage 3: a randomized controlled trial. Am J Kidney Dis. 2014; 64:222-229. [PubMed: 24776325]

46. Watson EL, Greening NJ, Viana JL, et al. Progressive resistance exercise training in CKD: a feasibility study. Am J Kidney Dis. 2015; 66:249-257. [PubMed: 25533601]

47. Balakrishnan VS, Rao M, Menon V, et al. Resistance training increases muscle mitochondrial biogenesis in patients with chronic kidney disease. Clin J Am Soc Nephrol. 2010; 5:996-1002. [PubMed: 20498251]

48. Barcellos FC, Santos IS, Umpierre D, et al. Effects of exercise in the whole spectrum of chronic kidney disease: a systematic review. Clin Kidney J. 2015; 8:753-765. [PubMed: 26613036]

49. Izumi A, Kitamura M, Izawa KP. Effects of exercise training on delaying disease progression in patients with chronic kidney disease: a review of the literature. Rev Recent Clin Trials. 2016; 11:333-341. [PubMed: 27457349]

50. Cheema BS, Chan D, Fahey P, Atlantis E. Effect of progressive resistance training on measures of skeletal muscle hypertrophy, muscular strength and health-related quality of life in patients with chronic kidney disease: a systematic review and meta-analysis. Sports Med. 2014; 44:1125-1138. [PubMed: 24696049]

51. Thomas M, Langley B, Berry C, et al. Myostatin, a negative regulator of muscle growth, functions by inhibiting myoblast proliferation. J Biol Chem. 2000; 275:40235-40243. [PubMed: 10976104]

52. Zhang L, Rajan V, Lin E, et al. Pharmacological inhibition of myostatin suppresses systemic inflammation and muscle atrophy in mice with chronic kidney disease. FASEB J. 2011; 25:16531663. [PubMed: 21282204]

53. Attie KM, Borgstein NG, Yang Y, et al. A single ascending-dose study of muscle regulator ACE-031 in healthy volunteers. Muscle Nerve. 2013; 47:416-423. [PubMed: 23169607]

54. Campbell C, McMillan HJ, Mah JK, et al. Myostatin inhibitor ACE-031 treatment of ambulatory boys with Duchenne muscular dystrophy: results of a randomized, placebo-controlled clinical trial. Muscle Nerve. 2016:1-7.

55. Woodhouse L, Gandhi R, Warden SJ, et al. A Phase 2 randomized study investigating the efficacy and safety of myostatin antibody LY2495655 versus placebo in patients undergoing elective total hip arthroplasty. J Frailty Aging. 2016; 5:62-70. [PubMed: 26980371]

56. Griggs RC, Kingston W, Jozefowicz RF, et al. Effect of testosterone on muscle mass and muscle protein synthesis. J Appl Physiol. 1989; 66:498-503. [PubMed: 2917954]

57. Johansen KL, Mulligan K, Schambelan M. Anabolic effects of nandrolone decanoate in patients receiving dialysis: a randomized controlled trial. JAMA. 1999; 281:1275-1281. [PubMed: 10208142]

58. Johansen KL, Painter PL, Sakkas GK, et al. Effects of resistance exercise training and nandrolone decanoate on body composition and muscle function among patients who receive hemodialysis: a randomized, controlled trial. J Am Soc Nephrol. 2006; 17:2307-2314. [PubMed: 16825332]

59. Supasyndh O, Satirapoj B, Aramwit P, et al. Effect of oral anabolic steroid on muscle strength and muscle growth in hemodialysis patients. Clin J Am Soc Nephrol. 2013; 8:271-279. [PubMed: 23124786]

60. Dalton JT, Barnette KG, Bohl CE, et al. The selective androgen receptor modulator GTx-024 (enobosarm) improves lean body mass and physical function in healthy elderly men and 
postmenopausal women: results of a double-blind, placebo-controlled phase II trial. J Cachexia Sarcopenia Muscle. 2011; 2:153-161. [PubMed: 22031847]

61. Crawford J, Prado CM, Johnston MA, et al. Study design and rationale for the phase 3 clinical development program of enobosarm, a selective androgen receptor modulator, for the prevention and treatment of muscle wasting in cancer patients (POWER trials). Curr Oncol Rep. 2016; 18:37. [PubMed: 27138015]

62. Taskapan H, Baysal O, Karahan D, et al. Vitamin D and muscle strength, functional ability and balance in peritoneal dialysis patients with vitamin D deficiency. Clin Nephrol. 2011; 76:110-116. [PubMed: 21762642]

63. Hansen TB, Gram J, Jensen PB, et al. Influence of growth hormone on whole body and regional soft tissue composition in adult patients on hemodialysis. A double-blind, randomized, placebocontrolled study. Clin Nephrol. 2000; 53:99-107. [PubMed: 10711411]

64. Guebre-Egziabher F, Juillard L, Boirie Y, et al. Short-term administration of a combination of recombinant growth hormone and insulin-like growth factor-I induces anabolism in maintenance hemodialysis. J Clin Endocrinol Metab. 2009; 94:2299-2305. [PubMed: 19401377]

65. Silva LC, Marinho PE. Knowledge among nephrologists about the importance of exercise in the intradialytic period. J Phys Ther Sci. 2015; 27:2991-2994. [PubMed: 26504342]

66. Delgado C, Johansen KL. Deficient counseling on physical activity among nephrologists. Nephron Clin Pract. 2010; 116:c330-c336. [PubMed: 20664289]

67. Silva SF, Pereira AA, Silva WA, et al. Physical therapy during hemodialyse in patients with chronic kidney disease. J Bras Nefrol. 2013; 35:170-176. [PubMed: 24100735]

68. Oliveros RM, Avendano M, Bunout D, et al. A pilot study on physical training of patients in hemodialysis. Rev Med Chil. 2011; 139:1046-1053. [PubMed: 22215335] 


\section{KEY POINTS}

- Sarcopenia is loss of skeletal muscle and has important consequences in $\mathrm{CKD}$, even prior to starting dialysis. Definitions for sarcopenia in CKD use a combination of lean muscle mass, strength and/or physical function.

- $\quad$ Sarcopenia in CKD is the negative balance between skeletal muscle breakdown and growth that is effected by the uremic environment.

- $\quad$ Although limited, there are therapeutic options intended to mitigate or improve skeletal muscle mass and function (i.e. sarcopenia) in predialysis CKD through physical (i.e. exercise and activity) and emerging pharmacological therapies.

- Overlapping terminologies and definitions that describe musculoskeletal dysfunction in CKD, including cachexia, frailty, protein-energy wasting, dynapenia and sarcopenia, can be confusing to many clinicians and researchers and limit their clinical utility. 


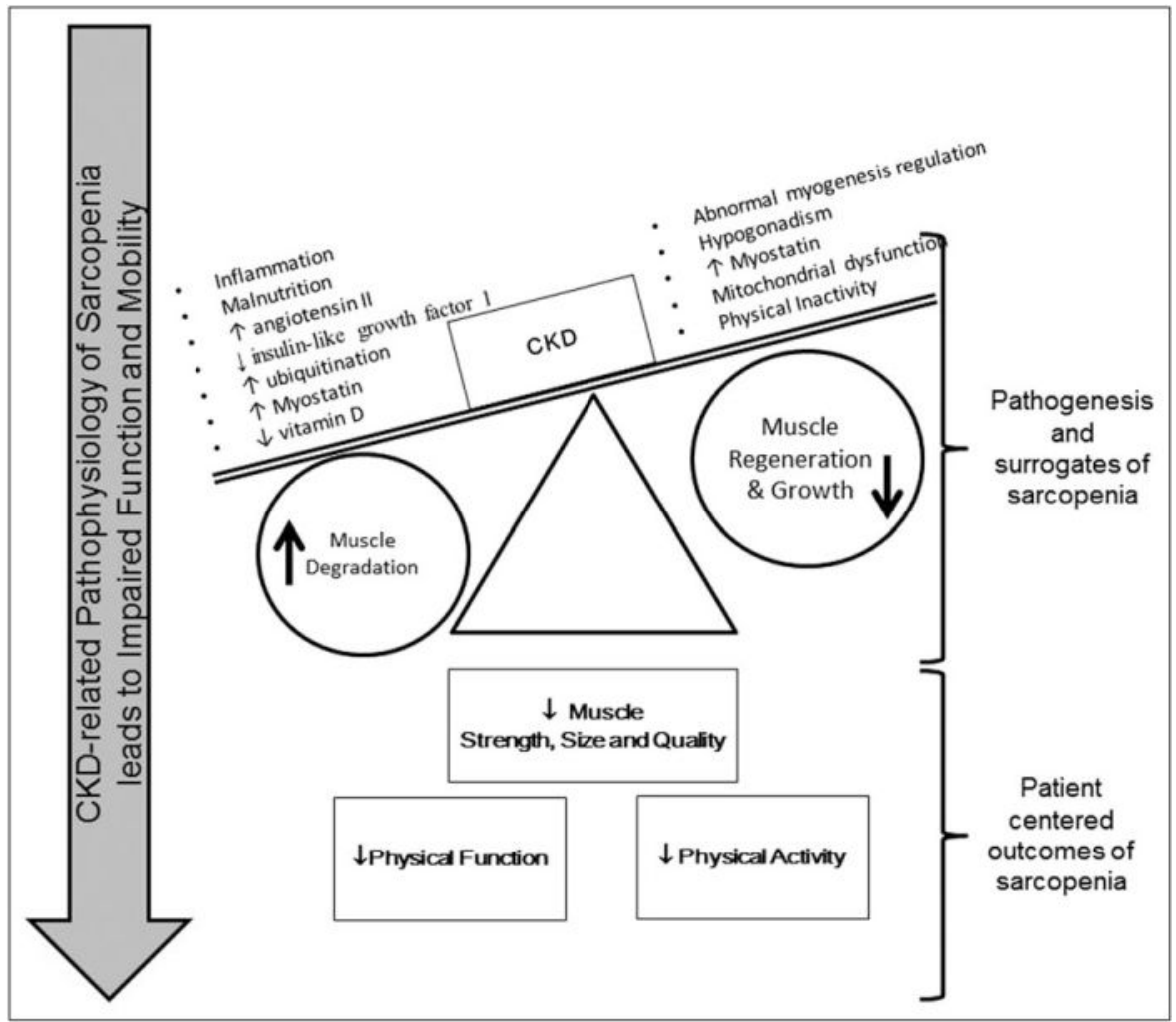

FIGURE 1.

The altered homeostasis in CKD negatively affects skeletal muscle mass, strength and quality. Skeletal muscle dysfunction has significant effects upon overall physical function and activity. 


\section{Table 1}

\section{Operational definitions of sarcopenia}

\begin{tabular}{|c|c|c|c|}
\hline Author & Appendicular lean mass & Gait & Physical performance \\
\hline Baumgartner et al. [9] & $\begin{array}{l}\text { Appendicular skeletal muscle mass/height }{ }^{2}>2 \mathrm{SD} \text { average of a } \\
\text { young reference population is sarcopenic threshold }\end{array}$ & & \\
\hline Newman et al. [10] & $\begin{array}{l}\text { A measure of relative } \mathrm{LM}(\mathrm{LM}, \mathrm{kg}) \text { was derived by adjusting } \\
\text { for fat mass }(\mathrm{FM}, \mathrm{kg}) \text { in addition to height }(\mathrm{m})\end{array}$ & & \\
\hline Delmonico et al. [11] & $\begin{array}{l}\text { Appendicular skeletal muscle mass/height }{ }^{2} \text { categorized by sex- } \\
\text { specific lowest } 20 \% \text { of the health aging and body composition } \\
\text { study }\end{array}$ & & \\
\hline $\begin{array}{l}\text { European Working Group } \\
\text { on Sarcopenia in Older } \\
\text { People [5] }\end{array}$ & $\begin{array}{l}\text { Low appendicular skeletal muscle mass using the } \\
\text { Baumgartner's criteria (ASM/height }{ }^{2} \leq .45 \mathrm{~kg} / \mathrm{m}^{2} \text { ) }\end{array}$ & $\begin{array}{l}\text { Gait speed } \\
\$ 0.8 \mathrm{~m} / \mathrm{s}\end{array}$ & $\begin{array}{l}\text { Grip strength cutoff of } 20 \mathrm{~kg} \\
\text { (via dynamometer) }\end{array}$ \\
\hline $\begin{array}{l}\text { European Society for } \\
\text { Clinical Nutrition and } \\
\text { Metabolism Special Interest } \\
\text { Group [12] }\end{array}$ & $\begin{array}{l}>2 \text { SD average of a young reference population for } \\
\text { appendicular skeletal muscle mass/height }{ }^{2}\end{array}$ & $\begin{array}{l}\text { Gait speed } \\
\$ 0.8 \mathrm{~m} / \mathrm{s}\end{array}$ & \\
\hline $\begin{array}{l}\text { International Working } \\
\text { Group on Sarcopenia [13] }\end{array}$ & $\begin{array}{l}\text { Appendicular skeletal muscle mass/height }{ }^{2} \text { categorized by sex- } \\
\text { specific lowest } 20 \% \text { of the health aging and body composition } \\
\text { study }\end{array}$ & $\begin{array}{l}\text { Gait speed } \\
\leq \mathrm{m} / \mathrm{s}\end{array}$ & \\
\hline $\begin{array}{l}\text { Foundation of NIH } \\
\text { Sarcopenia Project [6] }\end{array}$ & $\begin{array}{l}\text { Appendicular lean mass } \\
\text { Men: }<0.789 \\
\text { Women: }<0.512\end{array}$ & $\begin{array}{l}\text { Gait speed } \\
\unlhd 0.8 \mathrm{~m} / \mathrm{s}\end{array}$ & $\begin{array}{l}\text { Grip strength } \\
\text { Men: }<26 \mathrm{~kg} \\
\text { Women: }<16 \mathrm{~kg}\end{array}$ \\
\hline
\end{tabular}


Table 2

Clinically relevant measures of sarcopenia

\begin{tabular}{|c|c|c|c|c|}
\hline Assessment & Brief procedure & $\begin{array}{l}\text { Consideration with } \\
\text { CKD patients }\end{array}$ & $\begin{array}{l}\text { Example of } \\
\text { studies that used } \\
\text { this test in CKD } \\
\text { pop and } \\
\text { outcomes } \\
\text { (reference) }\end{array}$ & Summary of key result \\
\hline SPPB & $\begin{array}{l}\text { Composite score of standing balance, } \\
4 \mathrm{~m} \text { gait speed and sit-to-stand }\end{array}$ & $\begin{array}{l}\text { Cutoff unclear. Cannot } \\
\text { be performed in } \\
\text { wheelchair bound }\end{array}$ & Reese et al. [22] & $\begin{array}{l}\text { eGFR } 30-59 \text { was associated } \\
\text { with a } 0.51 \text { point lower SPPB } \\
\text { score, eGFR } 15-29 \text { was } \\
\text { associated with a } 0.61 \text { point } \\
\text { lower SPPB score, eGFR < } 15 \\
\text { was associated with a } 1.75 \\
\text { point lower SPPB score }\end{array}$ \\
\hline Usual gait speed & $\begin{array}{l}\text { Measure a distance of } 4 \mathrm{~m} \text { with } 5 \mathrm{ft} \text {. } \\
\text { start/end area; instruct patient to 'walk } \\
\text { at a comfortable pace'. Patient } \\
\text { performs } \times 2 \text { repetitions; fastest time } \\
\text { recorded }\end{array}$ & $\begin{array}{l}\text { Cutoff unclear. Cannot } \\
\text { be performed in } \\
\text { wheelchair bound } \\
\text { without a prostheses }\end{array}$ & $\begin{array}{l}\text { Roshanravan et al. } \\
{[17]}\end{array}$ & $\begin{array}{l}0.1 \mathrm{~m} / \mathrm{s} \text { drop associated with } \\
26 \% \text { higher risk of death }\end{array}$ \\
\hline 30s sit-to-stand & $\begin{array}{l}\text { Participant is seated in middle of } \\
\text { armless chair with feet shoulder width } \\
\text { apart and arms are crossed at the } \\
\text { chest. Participant is encouraged to } \\
\text { complete as many full stands as } \\
\text { possible within } 30 \text { s }\end{array}$ & $\begin{array}{l}\text { Minimal detectable } \\
\text { change and cutoff } \\
\text { scores not established in } \\
\text { CKD }\end{array}$ & Hsiao et al. [23] & $\begin{array}{l}\text { Patients with stages } 1-5 \text { CKD } \\
\text { had lower } 30 \text {-s chair-stand } \\
\text { scores were associated with } \\
\text { high fluid status, high fat } \\
\text { tissue index and lower lean } \\
\text { tissue than those with }(P< \\
0.002)\end{array}$ \\
\hline Grip strength & $\begin{array}{l}\text { Assessed in the participant's dominant } \\
\text { hand, the mean from three consecutive } \\
\text { efforts with minimum of } 60 \text {-s rest. } \\
\text { Arm position should be consistent } \\
\text { (flexed/extended elbow) }\end{array}$ & $\begin{array}{l}\text { Minimal detectable } \\
\text { change and cutoff } \\
\text { scores not established in } \\
\text { CKD }\end{array}$ & $\begin{array}{l}\text { Roshanravan et al. } \\
{[17]}\end{array}$ & $\begin{array}{l}\text { Lowest predictor of death } \\
\text { when compared with lower } \\
\text { extremity function (timed-up- } \\
\text { and-go, gait speed and 6-min } \\
\text { walk test) }\end{array}$ \\
\hline Timed-up-and-go & $\begin{array}{l}\text { Patient rises from a on the command } \\
\text { 'go' and walks } 3 \mathrm{~m} \text { (safe pace) turns, } \\
\text { walks back and sits in chair. Time } \\
\text { begins at 'go', stops when the patient } \\
\text { is seated }\end{array}$ & $\begin{array}{l}\text { Cutoff score in } \\
\text { community- dwelling } \\
\text { older adults: }>13.5 \mathrm{~s} \text {; in } \\
\text { frail older adults: } 32.6 \mathrm{~s}\end{array}$ & $\begin{array}{l}\text { Roshanravan et al. } \\
{[17]}\end{array}$ & $\begin{array}{l}\text { For each } 1 \mathrm{~s} \text { longer on the } \\
\text { timed-up- and-go, there was an } \\
\text { associated } 8 \% \text { higher risk for } \\
\text { death }\end{array}$ \\
\hline
\end{tabular}

CKD, chronic kidney disease; eGFR, estimated glomerular filtration rate; SPPB, Short Physical Performance Battery. 


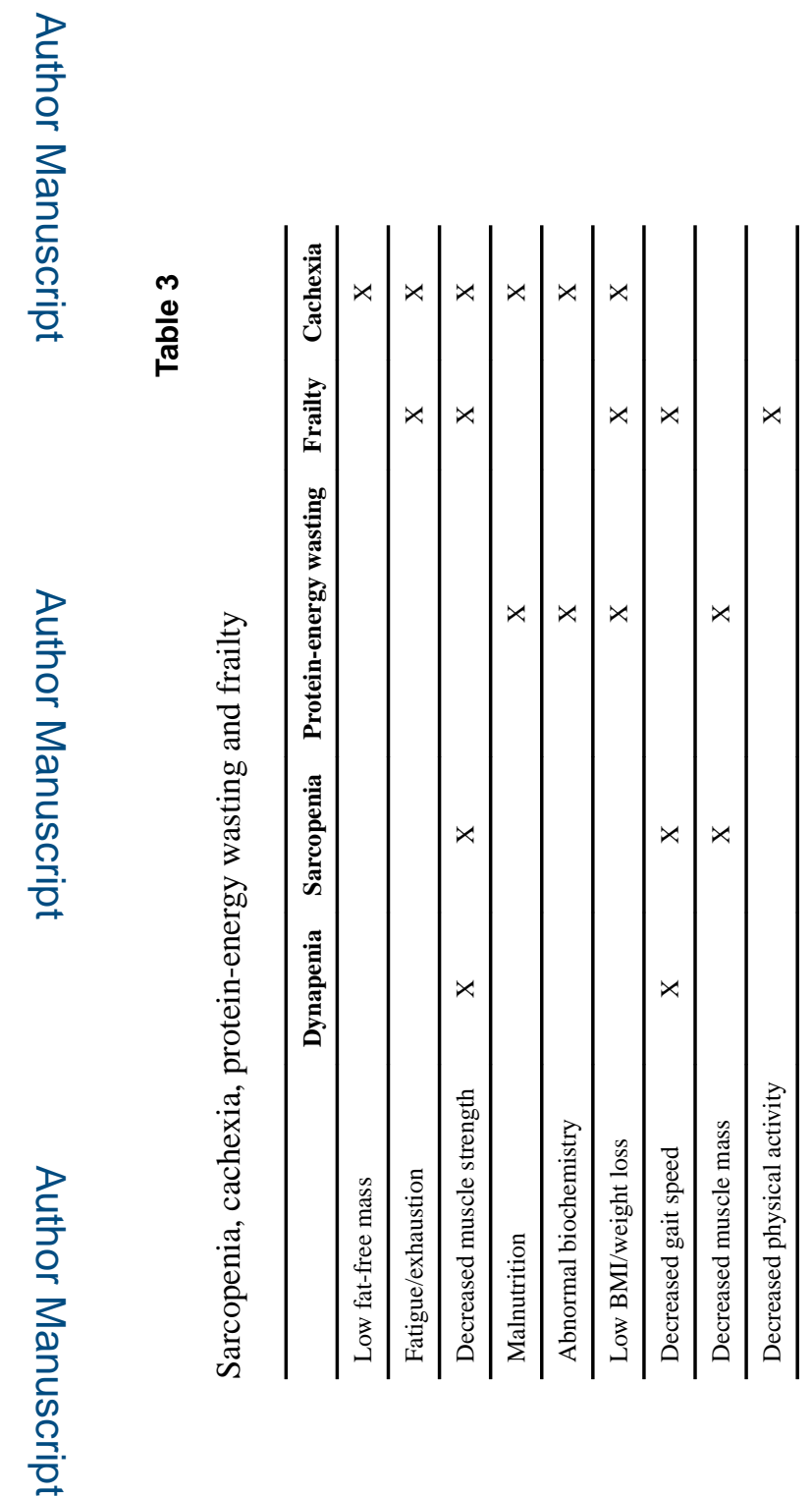

Curr Opin Nephrol Hypertens. Author manuscript; available in PMC 2018 March 20. 


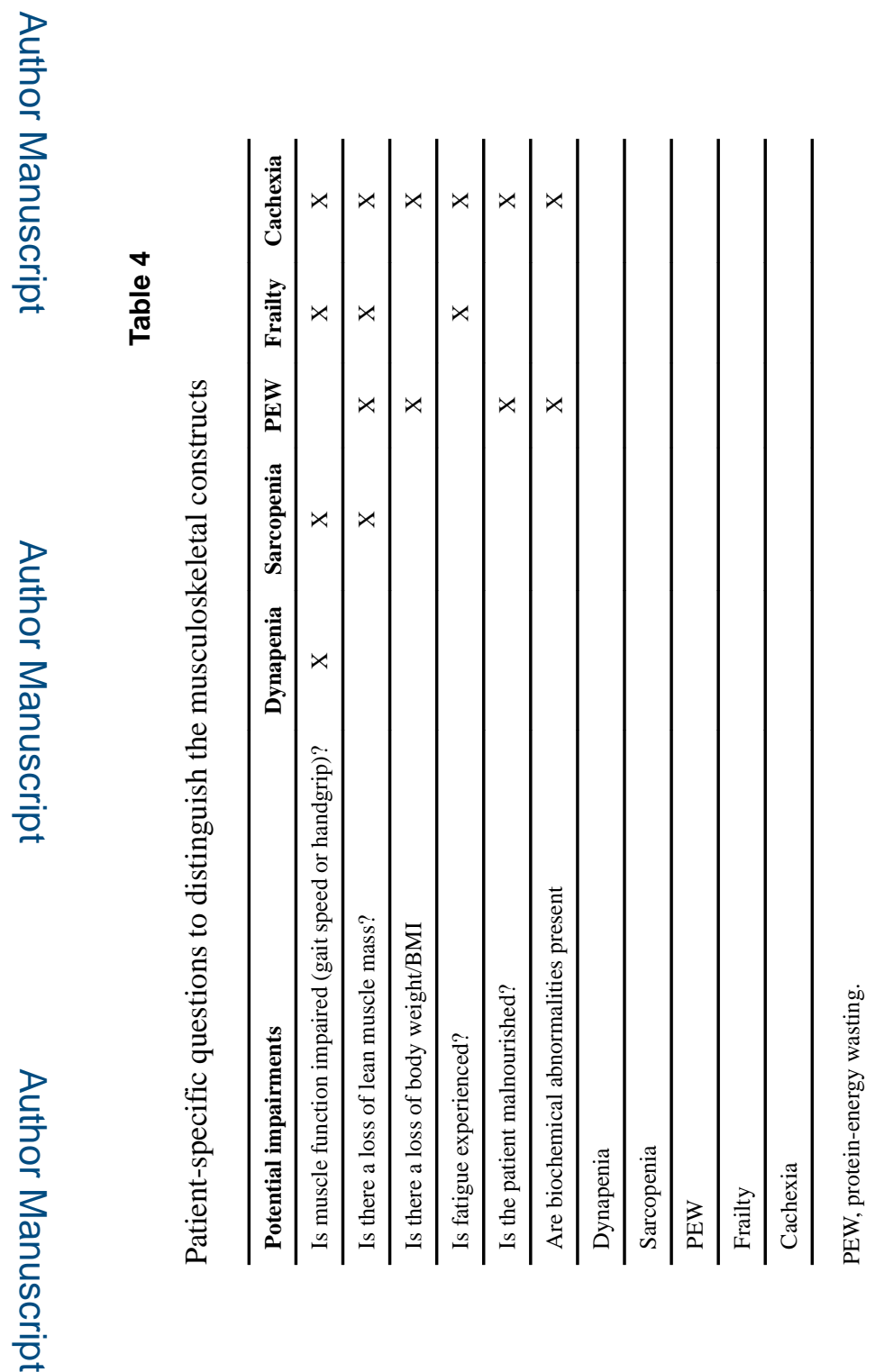




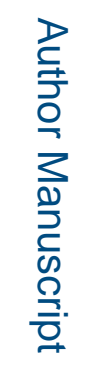

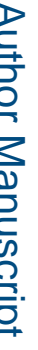

ב

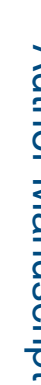

을

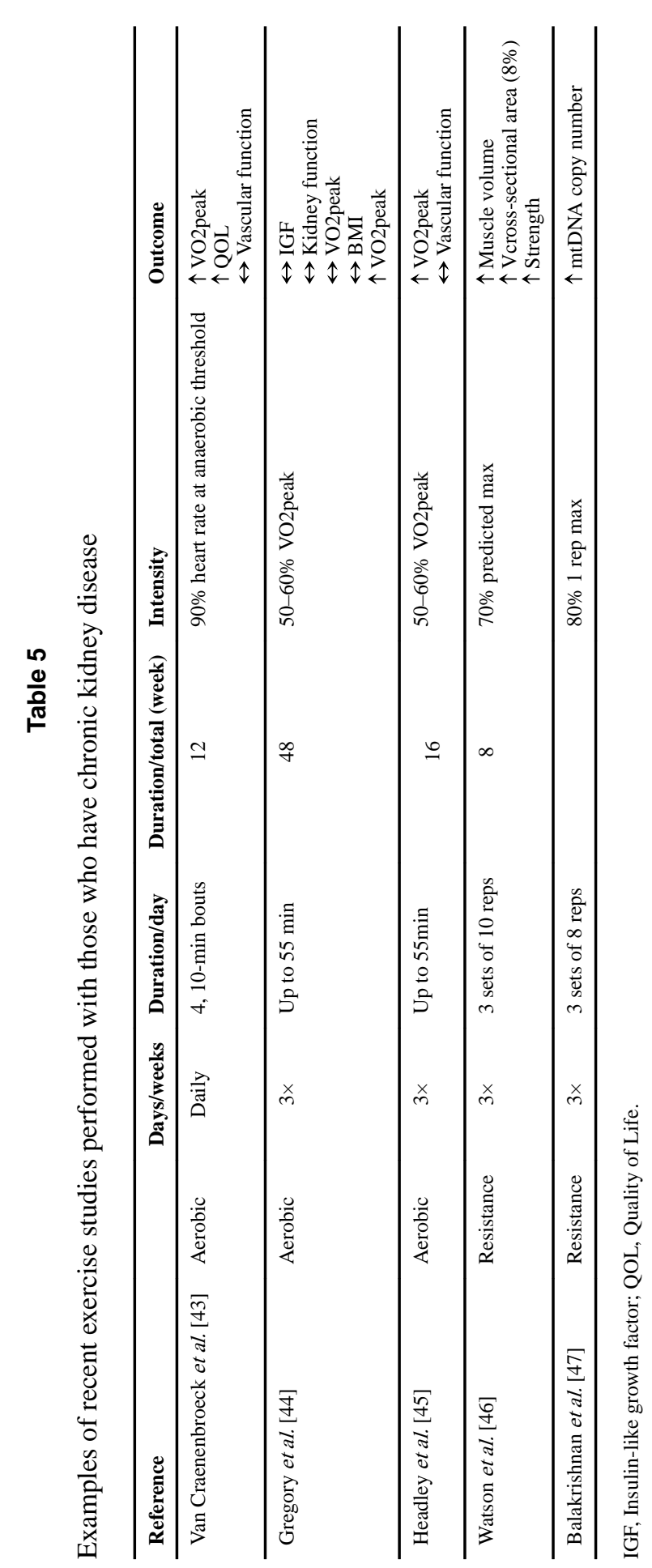

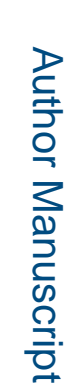

